\title{
Numerical Simulation of Damage on Warm Deep Drawing of Al 6061-T6 Aluminium Alloy
}

\author{
W. Rajhi \\ University of Hail, College of Engineering, Hail, Saudi Arabia and \\ Laboratoire de Mecanique, Ecole Nationale Superieure d'Ingenieurs de Tunis, Universite de Tunis, Tunisia \\ wajdirajhi@gmail.com
}

\begin{abstract}
This work focuses on the numerical simulation of warm deep drawing operation of car sump oil made with Al 6061-T6 aluminum alloy for the purpose of process optimization. The thermo visco-plastic behavior with damage effect of the material is described by the Johnson-Cook (JC) model. The JC model parameters for the Al 6061-T6 Aluminum alloy were exploited. Numerical simulation of the deep drawing operation was performed with the use of the ABAQUS FE software thanks to the dynamic Explicit Temperature-Displacement algorithm. The design of the different tools is obtained on the basis of the geometry of the finished product. Designing of punch, die and blank holder is performed using CATIA 3D CAD software. The warm forming method involves the heating of the blank holder and the die to a certain temperature, whereas, the punch is kept at room temperature. In this study, predefined temperatures of the die and blank holder and punch speed will be investigated among other stamping parameters. The computed damage evolution curves for a given set of the process parameters are retrieved at the end of the simulation to determine suitable forming conditions. It can be noted that the slower the damage evolution achieved within the blank, the more appropriate the process parameters. Thus, by increasing strain rate, main cracks change location. The dynamic explicit temperature-displacement algorithm available in Abaqus is used to solve the equilibrium problem with temperature effect in order to investigate the appropriateness of the process parameters on the basis of the computed damage-displacement curves.
\end{abstract}

Keywords-warm deep drawing; car sump oil; Johnson-Cook model; optimization; numerical simulation

\section{INTRODUCTION}

Aluminum alloy sheet metal is characterized by its good weight to strength ratio. However, one shortcoming of aluminum is its low malleability compared to mild steel which is widely used in sheet metal forming. Thus, costly multi-step manufacture processes are required to obtain intricate product geometries with aluminum alloys [1]. One technique to prevent such difficulty is the deep drawing at high temperatures $[2,3]$. Accordingly, the sheet metal forming of aluminum alloys may be enhanced considerably, as the number of required production phases can be limited. Regarding car sump oil application, certain conditions and obligations in relation to certain physical proprieties and mechanical characteristics of the component material have to be met. The material of the sump should provide better corrosion resistance. Even if the oil sump is not intended for cooling, better material thermal conductivity improves further the performance of the component. Moreover, it should offer a good ductility or toughness to avoid crack or damage formation due to contact with obstacles. In addition, low material density represents an excellent benefit, since it alleviates the weight of the sump. This study is devoted to the prediction of damage for the purpose of optimization of the warm deep drawing operation of car sump oil made with Al 6061-T6 aluminum alloy which meets all the above requirements $[4\rceil$. Once the final geometry of the car sump oil is provided, CATIA 3D is used to design the finished product and thereby the corresponding tools set. Thus, the different tool parts are imported from CATIA to ABAQUS wherein several numerical simulations of stamping are performed while varying operating process parameters, principally the blank holder, the die temperatures, and the punch speed. The thermo mechanical behavior with strain rate and damage effects of the Al 6061-T6 aluminum alloy is described under deep drawing loading conditions by JC thermo visco-plastic model through a well-defined set of JC model parameters garnered from previous works $\lceil 5,6\rceil$. The dynamic explicit temperature-displacement algorithm available in Abaqus is used to solve the equilibrium problem with temperature effect in order to investigate the basis of the computed damage-displacement curves and the appropriateness of the process parameters.

\section{CAR SUMP OIL DESIGN AND THE CORRESPONDING TOOLS}

This section is devoted to a brief summary of the principal steps allowing the design under CATIA software of the car sump oil and the corresponding stamping tools. Figure 1 illustrates the 2D detail drawing of the car sump. It provides the detailed description of the finished part geometry with all required dimensions which should be obtained at the end of the deep drawing operation. The finished part designed in CATIA is given in Figure 2. Three tools are required to achieve a deep drawing operation: the punch, the die and the blank holder. Their geometries are obtained from the finished design of the car oil sump part (Figure 2), defined as:

- A recessed die corresponding to the outer form of the car sump.

- A punch, in relief, conforming to the inner shape of the part while preserving the sheet thickness. Therefore, a clearance between the die and the punch is required which should be 
somewhat superior to the thickness of the stamped sheet. In this study, the clearance is a fixed process parameter, given by $c=e+0.5$ with $e$ representing the thickness of the blank.

- A blank holder encloses the punch which is placed against the border of the die allowing clamping the blank during the displacement of the punch. The geometry of the die, the punch, and the blank holder are given in Figure 3.
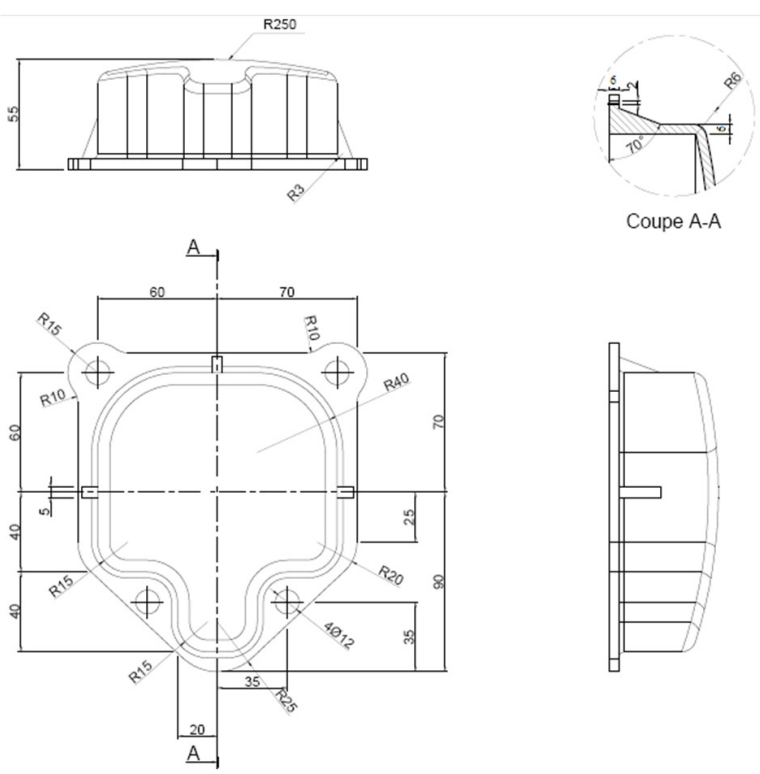

Coupe A-A

Fig. 1. 2D detail drawing of the car sump

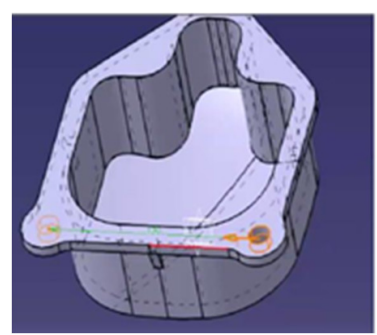

Fig. 2. Design of the car sump

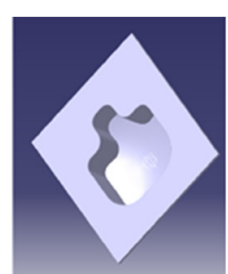

(a)

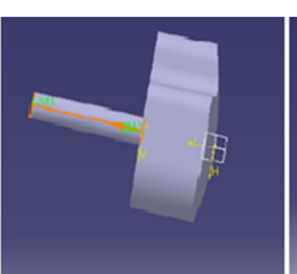

(b)

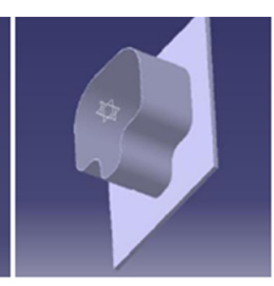

(c)
Fig. 3. Design under CATIA of (a) die, (b) punch, and (c) blank holder

The design of the car oil sump and the corresponding tools shown in Figures 2 and 3 requires several geometric operations on CATIA. For the removal and shaping of material, tools such as pocket and hole were used. Tools such as symmetry and circular repetitions were utilized. The main geometrical modeling steps are:

- Generation of the casing shape by extrusion and revolution
- Using a pocket to empty the housing core

- Making the fixing holes (hole with circular repetition), despite they are not requested in this analysis

\section{THERMO-MECHANICAL BEHAVIOR OF AL 6061-T6 ALUMINUM ALLOY}

In this study the temperature dependence of the elastic behavior of Al 6061-T6 aluminum alloy is considered. Moreover, the temperature dependence of the physical and thermal proprieties of the materiel such as density, thermal conductivity, heat capacity and thermal expansion were taken into consideration during the numerical simulation of the deep drawing operation. The evolution of the cited above physical, thermal and elastic material proprieties as temperature increases up to the melting point of the material are given in Figure 4.

(a)

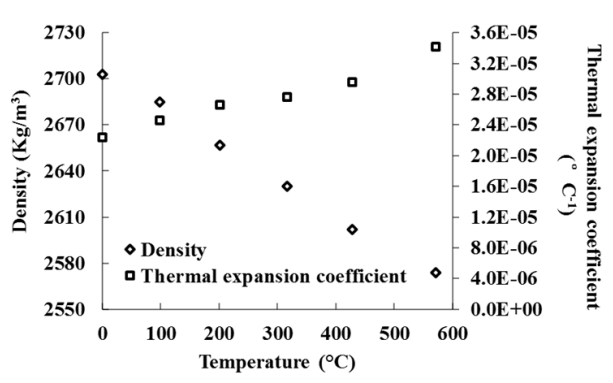

(b)
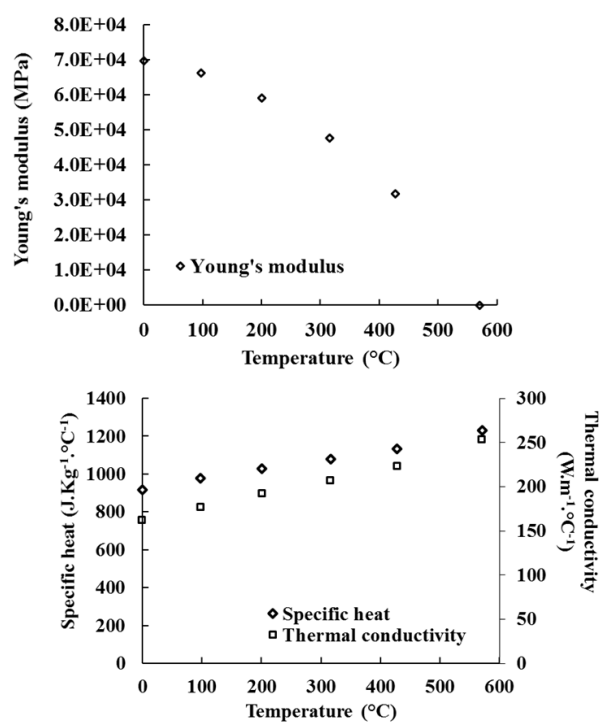

Fig. 4. Material properties with temperature dependance of 6061-T6 aluminum alloy. Data were taken from [5]

Thus, the JC constitutive model with the damage effect is used in this work to describe the thermo plastic behavior with strain rate effect (viscosity) of the blank accounting for material softening and failure under deep drawing loading conditions. It is worth noting that constitutive models based on thermodynamic of irreversible process [7-9] result in a more accurately damage prediction once the strain rate effect is taken 
into consideration [10]. The JC flow stress relation accounting for temperature and strain rate effect is given by:

$$
\sigma=\left[A+B\left(\varepsilon^{p}\right)^{n}\right]\left[1+C \ln \left(\frac{\dot{\varepsilon}^{p}}{\dot{\varepsilon}^{0}}\right)\right]\left[1-\left(\frac{T-T_{0}}{T_{\text {melt }}-T_{0}}\right)\right](1)
$$

Equation (1) includes five materials constants: the yield stress $A$, the hardening modulus $B$, the strain-hardening coefficient $n$, the viscosity parameter $C$, and the thermal sensitivity $m$. Constants $B$ and $n$ describe the flow stress with hardening effect. $T_{o}$ and $T_{\text {melt }}$ are respectively the room temperature and the melting temperature, while $\dot{\varepsilon}^{0}$ is the reference strain rate. The $A, B, C, n$ and $m$ JC material parameters of the Al 6061-T6 aluminum alloy used in the present study are reported in Table I.

TABLE I. PLASTIC PARAMETERS OF JC CONSTITUTIVE MODEL FOR AL 6061-T6 ALUMINUM ALLOY [5]

\begin{tabular}{|c|c|c|c|c|c|c|}
\hline $\boldsymbol{A}$ (MPA) & $\boldsymbol{B}$ (MPa) & $\boldsymbol{n}$ & $\boldsymbol{C}$ & $\boldsymbol{m}$ & $\dot{\boldsymbol{\varepsilon}}^{\mathbf{0}}$ & Melting point $\left({ }^{\circ} \mathbf{C}\right)$ \\
\hline 324 & 114 & 0.42 & 0.0083 & 1.34 & 1 & 582 \\
\hline
\end{tabular}

The JC failure criterion is used to describe ductile damage evolution within the Al 6061-T6 aluminum alloy sheet metal under stamping conditions:

$$
\begin{gathered}
\varepsilon_{f}=\left[D_{1}+D_{2} E X P\left[D_{3}\left(\frac{P}{S}\right)\right]\right]\left[1+D_{4} \ln \left(\frac{\dot{\varepsilon}^{p}}{\dot{\varepsilon}^{0}}\right)\right][1+ \\
\left.D_{5}\left(\frac{T-T_{0}}{T_{\text {melt }}-T_{0}}\right)\right]
\end{gathered}
$$

The parameters of JC failure criterion for the Al 6061-T6 aluminum alloy are reported in Table II.

TABLE II. DAMAGE PARAMETERS OF JC CONSTITUTIVE MODEL FOR AL 6061-T6 ALUMINUM ALLOY [6]

\begin{tabular}{|c|c|c|c|c|}
\hline $\boldsymbol{D}_{1}$ & $\boldsymbol{D}_{2}$ & $\boldsymbol{D}_{3}$ & $\boldsymbol{D}_{4}$ & $\boldsymbol{D}_{5}$ \\
\hline-0.77 & 1.45 & -0.47 & 0 & 1.6 \\
\hline
\end{tabular}

\section{CAR SUMP OIL DEEP DRAWING FINITE ELEMENT MODEL}

We are interested in the numerical simulation of the deep drawing operation of the crater using the dynamic explicit temperature-displacement algorithm available in ABAQUS FE software. Therefore, the different tool parts given in Figure 3 are imported to ABAQUS from CATIA. In this study, the tools are considered as discrete rigid parts and their meshing is carried out using R3D4 (4-node 3-D bilinear rigid quadrilateral) rigid element type (Figure 5). Thus, the same element size of about $8 \mathrm{~mm}$ has been adopted to mesh the die, the punch, and the blank holder. The simulated Al 6061-T6 aluminum alloy sheet metal with dimensions of $400 \times 400 \times 6 \mathrm{~mm}^{3}$ is shown in Figure 5. The thermo-elastic behavior of the sheet metal under stamping conditions is described by the A1 6061-T6 alloy data shown in Figure 4. The plastic behavior is dependent to both temperature and strain rate effects and defined by JC constitutive model presented above including the model parameters reported in Table I [5, 6]. The blank is meshed with 3D solid element type C3D8T using only one element through thickness (an 8-node thermally coupled brick, trilinear displacement and temperature), with minimum mean size of $2 \mathrm{~mm}$. The blank holder is placed over the blank, i.e. no operating forces are applied on the blank holder. A friction coefficient $\mu=0.05$ is defined between the upper face of the blank and the down surface of the blank holder and each of down and side surfaces of the punch. The same friction coefficient value is adopted to define the contact between the lower surface of the blank and the inner surfaces of the die.
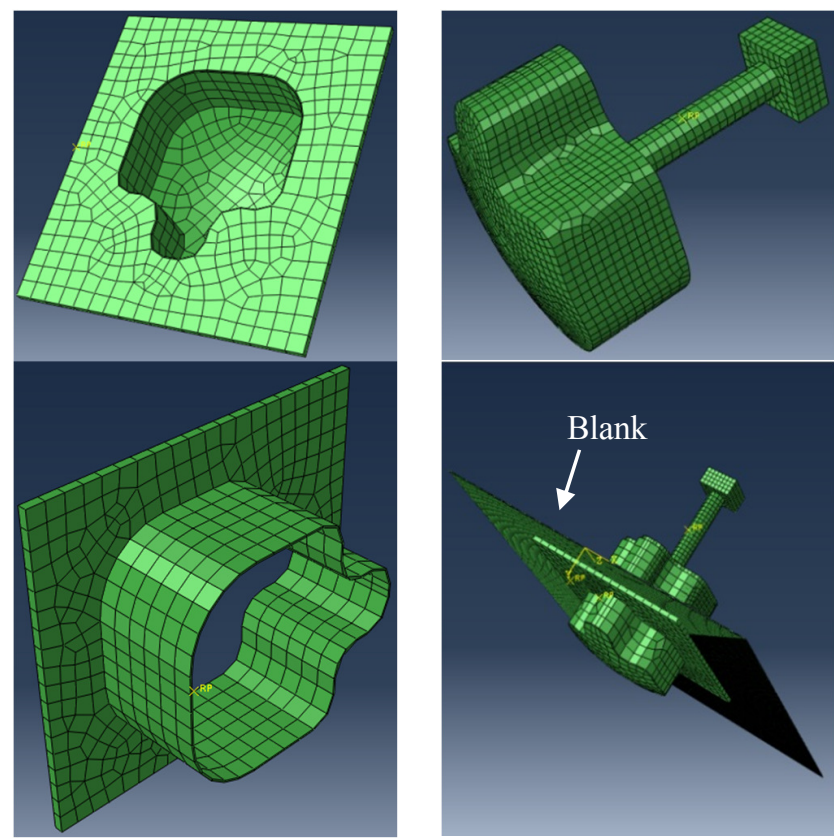

Fig. 5. 3D mesh of the the blank and the tool parts

The punch velocity $V$ is considered as one of the main setting parameters for the deep drawing operation, thereby its value is altered in order to investigate such parameter effect on damage evolution. The blank under stamping condition is subjected to a strain rate magnitude which may be defined as the ratio between the operating punch velocity and the total punch displacement during which the contact between the punch and the blank is maintained. Since the total displacement of the punch is constant, the magnitude is none other than that the stamping depth $s_{d}=55 \mathrm{~mm}$, hence, according to a strain rate reference value of $1 \mathrm{~s}^{-1}$, a reference value of punch velocity $V_{p r}$ of about $55 \mathrm{~mm} / \mathrm{s}$ will be adopted. The warm deep drawing process involves that the different stamping tools are preheated and thermally insulated. In this work, the temperature of the punch is kept constant and close to room temperature throughout all stamping simulations. The preselected temperatures $T_{0}$ of blank holder and die which represent the second setting parameter for this study are considered the same and altered from one calculation to another. Therefore, various temperature levels are assigned to both the die and blank holder ranging between room temperature and $2 / 3$ of melting temperature of the aluminum alloy under investigation. The settings of stumping parameters are illustrated in Table III.

TABLE III. SELECTED STAMPING CONDITIONS FOR NUMERICAL SIMULATION

\begin{tabular}{|c|c|c|c|c|c|}
\hline$\dot{\boldsymbol{\varepsilon}}\left(\mathbf{s}^{-1}\right)$ & $\boldsymbol{V}(\mathbf{m m} / \mathbf{s})$ & $\boldsymbol{T}_{\boldsymbol{0}}{ }^{\text {rom }}\left({ }^{\circ} \mathbf{C}\right)$ & $\boldsymbol{T}_{\boldsymbol{0}}{ }^{\boldsymbol{}}\left({ }^{\circ} \mathbf{C}\right)$ & $\boldsymbol{T}_{\boldsymbol{0}}{ }^{2}\left({ }^{\circ} \mathbf{C}\right)$ & $\boldsymbol{T}_{\boldsymbol{0}}{ }^{3}\left({ }^{\circ} \mathbf{C}\right)$ \\
\hline 0.02 & 1.1 & 25 & 100 & 200 & 400 \\
\hline 1 & 55 & 25 & 100 & 200 & 400 \\
\hline 100 & 5500 & 25 & 100 & 200 & 400 \\
\hline
\end{tabular}




\section{RESULTS}

Several numerical simulations of car sump oil stamping operation were performed accounting for the process sittings reported in Table III. The distributions mapping of VOM equivalent stress, damage and temperature for setting parameters $\left(1 \mathrm{~s}^{-1}, 25^{\circ} \mathrm{C}\right)$ are illustrated in Figure 6. These distributions were retrieved before the end of the simulation while showing a wide region of meshing elements fully damaged (see Figure 6(b)). Thus, cracks within the blank having different sizes occurring in the neighborhood of the die shoulder were initially detected (Figure 7).

(a)

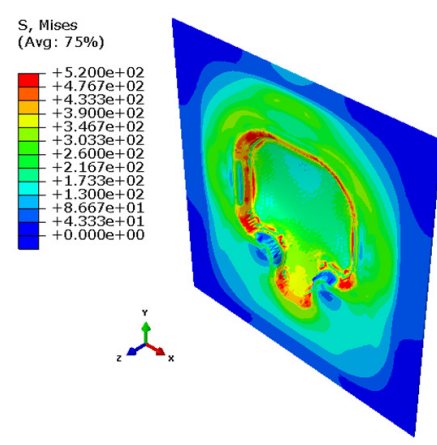

(b)

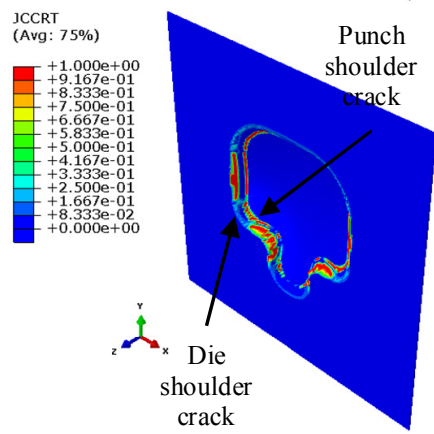

(c)

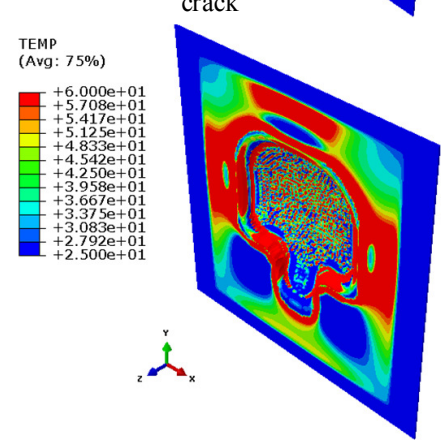

Fig. 6. Distribution mapping of (a) VOM equivalent stress, (b) damage, and (c) temperature obtained during stamping simulation for stamping conditions $\left(1 \mathrm{~s}^{-1}, 25^{\circ} \mathrm{C}\right)$

The computed damage-displacement evolution curves within the area of mesh elements of the blank located neighborhood to the die shoulder were obtained for the magnitude $V_{1}$ of punch velocity for temperature of the die and the blank holder ranging from room temperature to $400^{\circ} \mathrm{C}$ (Table III) and are shown in Figure 8. It can be noted that there is no significant effect of the die and blank holder temperature on the damage evolution neighborhood to the die shoulder during stamping operation. The same observations about the effect of the variation of the die and blank holder temperature regarding damage evolution are valid for punch velocities $V_{2}$ and $V_{3}$.

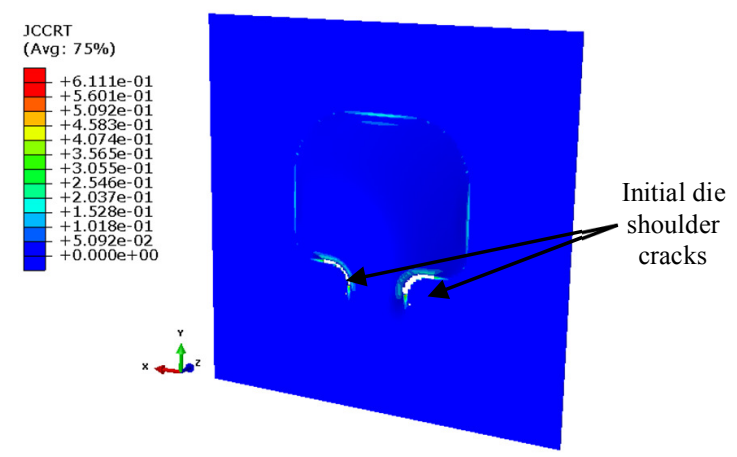

Fig. 7. Crakcs initiation neighborhood to the die shoulder for stamping conditions $\left(1 \mathrm{~s}^{-1}, 100^{\circ} \mathrm{C}\right)$

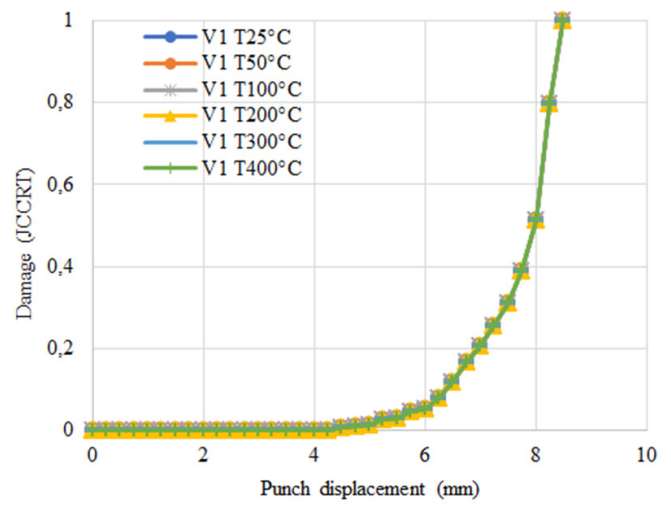

Fig. 8. Effect of die and blank holder operating temperature on the damage evolution within the blank

The effect of punch velocity on damage evolution for setting temperature $100^{\circ} \mathrm{C}$ is illustrated in Figure 9.

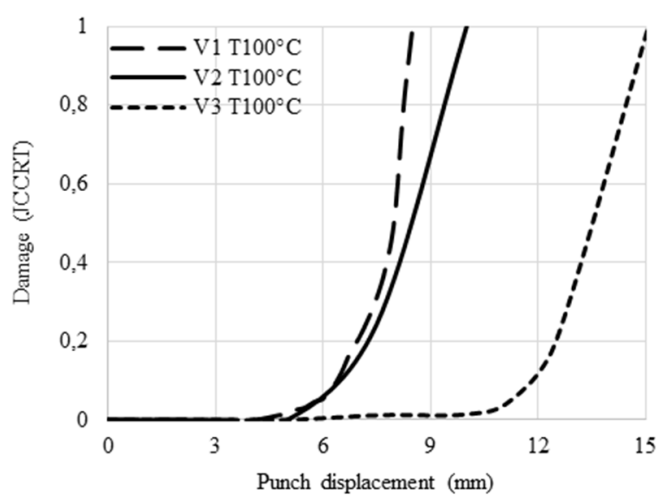

Fig. 9. Effect of punch velocity on damage evolution in deep drawing of Al 6061-T6

For punch velocity settings $V_{1}$ and $V_{2}$, the damage evolution neighborhood to die shoulder can be considered the same. The damage decelerates for punch velocity $V_{3}$. Similar observations were made for operating temperatures $25,200,300$ and $400^{\circ} \mathrm{C}$. 
Hence, it can be noted that for a given operating temperature, according to the plastic and damage JC parameters given in Tables I and II respectively, the higher the strain rate the slower the initial damage or main crack occurrence in the die shoulder neighborhood in the deep drawing of Al 6061-T6. It can be also noted that for deep drawing at high strain rate, the main cracks change their location from the die shoulder zone to the punch shoulder zone, which explains why damage decelerates in the die shoulder neighborhood for punch speed $V_{3}$.

\section{CONCLUSION}

In this work, JC visco-plastic model with damage effect is used to predict damage and crack formation in warm deep drawing of car sump oil made with aluminum alloy Al 6061T6. Several deep drawing numerical simulations were carried out altering die and blank holder operating temperature as well as punch velocity in order to investigate damage initiation in the blank for purpose of process optimization. It has been found that preheating the die and blank holder had not significant effect on damage evolution within the zone where the cracks initiate. However, punch velocity influences damage evolution within such critical zone, so that, an increase in strain rate results in a change in the cracks location.

\section{ACKNOWLEDGMENT}

The author would like to acknowledge the Research Deanship of the University of Hail for supporting this study under the Project No. 0160641.

\section{REFERENCES}

[1] M. Packo, M. Dukat, T. Sleboda, M. Hojny, "The analysis of multistage deep drawing of AA5754 aluminum alloy", Archives of Metallurgy and Materials, Vol. 55, No. 4, pp. 1173-1184. 2010

[2] G. Venkateswarlu, M. J. Davidson, G. R. N. Tagore, "Finite element simulation of deep drawing of aluminium alloy sheets at elevated temperatures", ARPN Journal of Engineering and Applied Sciences, Vol. 5, No. 7, pp. 93-98, 2010

[3] G. Ambrogio, L. Filice, G. Palumbo, S. Pinto, "Enhancing LDR in deep drawing by superimposing thermal gradients", 8th International Conference on Numerical Methods in Industrial Forming Processes, Columbus, USA, June 13-17, 2004

[4] B. M. Dariani, G. H. Liaghat, M. Gerdooei, "Experimental investigation of sheet metal formability under various strain rates", Proceedings of the Institution of Mechanical Engineers, Part B: Journal of Engineering Manufacture, Vol. 223, No. 6, pp. 703-712, 2009

[5] H. Seli, M. Awang, M. Awang, A. I. M. Ismail, E. Rachman, Z. A Ahmad, "Evaluation of properties and FEM Model of the Friction welded mild Steel-Al6061-Alumina", Materials Research, Vol. 16, No. 2, pp. 453-467, 2012

[6] L. E. Schwer, "Aluminum plate perforation: a comparative case study using Lagrange with erosion, Multi-Material ALE, and Smoothed Particle hydrodynamics", 7th European LS-DYNA Conference, Salzburg, Austria, May 14-15, 2009

[7] H. Badreddine, C. Labergere, K. Saanouni, W. Rajhi, A. Rassineux, D. Kircher, "FE elastoplastic damage model with $2 \mathrm{D}$ adaptive remeshing procedure for fracture prediction in metal forming simulation", International Journal of Material Forming, Vol. 1, Suppl. 1, pp. 109-112, 2008

[8] W. Rajhi, K. Saanouni, H. Sidhom, "Anisotropic ductile damage fully coupled with anisotropic plastic flow: Modeling, experimental validation, and application to metal forming simulation", International Journal of Damage Mechanics, Vol. 23, No. 8, pp. 1211-1256, 2014

[9] W. Rajhi, B. Ayadi, A. Alghamdi, N. Messaoudene, "An Anisotropic Elastic-plastic Model for the Optimization of a Press Machine's
Auxiliary Worktable Plate Thickness", Engineering, Technology \& Applied Science Research, Vol. 8, No. 2, pp. 2764-2769, 2018

[10] K. Saanouni, Damage Mechanics in Metal Forming: Advanced Modeling and Numerical Simulation, John Wiley, 2012 